2 Article Type: XX (Miscellaneous)

3 Addendum guidelines for the

${ }_{4}$ prevention of peanut allergy in the

${ }_{5}$ United States

6

7 Summary of the National Institute of Allergy and

8 Infectious Diseases-sponsored expert panel

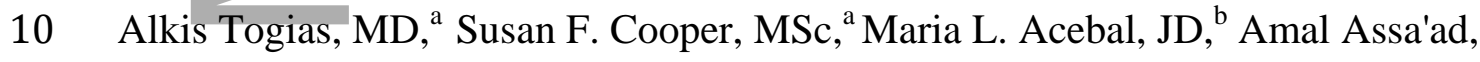

$11 \mathrm{MD},{ }^{\mathrm{c}}$ James R. Baker Jr., MD, ${ }^{\mathrm{d}}$ Lisa A. Beck, MD, ${ }^{\mathrm{e}}$ Julie Block, ${ }^{\mathrm{f}}$ Carol Byrd-Bredbenner,

$12 \mathrm{PhD}, \mathrm{RD}, \mathrm{FAND},{ }^{\mathrm{g}}$ Edmond S. Chan, MD, FRCPC, ${ }^{\mathrm{h}}$ Lawrence F. Eichenfield,

$13 \mathrm{MD},{ }^{\mathrm{i}}$ David M. Fleischer, MD,${ }_{\mathrm{j}}$ George J. Fuchs III, MD, ${ }^{\mathrm{k}}$ Glenn T. Furuta,

$14 \mathrm{MD},{ }^{1}$ Matthew J. Greenhawt, MD, MBA, MSc,${ }^{j}$ Ruchi S. Gupta, MD, MPH, ${ }^{\mathrm{m}}$ Michele

15 Habich, DNP, APN/CNS, CPN, ${ }^{\mathrm{n}}$ Stacie M. Jones, MD, ${ }^{\circ}$ Kari Keaton, ${ }^{\mathrm{p}}$ Antonella Muraro,

$16 \mathrm{MD}, \mathrm{PhD},{ }^{\mathrm{q}}$ Marshall Plaut, MD, ${ }^{\mathrm{a}}$ Lanny J. Rosenwasser, MD, ${ }^{\mathrm{r}}$ Daniel Rotrosen,

$17 \mathrm{MD},{ }^{\mathrm{a}}$ Hugh A. Sampson, MD, ${ }^{\mathrm{s}}$ Lynda C. Schneider, MD, ${ }^{\mathrm{t}}$ Scott H. Sicherer, MD, ${ }^{\mathrm{u}}$ Robert

18 Sidbury, MD, MPH, ${ }^{\mathrm{v}}$ Jonathan Spergel, MD, PhD, ${ }^{\mathrm{w}}$ David R. Stukus, MD,${ }^{\mathrm{x}}$ Carina Venter,

$19 \mathrm{PhD}, \mathrm{RD},{ }^{\mathrm{y}}$ Joshua A. Boyce, $\mathrm{MD}{ }^{\mathrm{z}}$

This is the author manuscript accepted for publication and has undergone full peer review but has not been through the copyediting, typesetting, pagination and proofreading process, which may lead to differences between this version and the Version of Record. Please cite this article as doi: $10.1111 /$ pde.13092

This article is protected by copyright. All rights reserved 
$21{ }^{a}$ National Institute of Allergy and Infectious Diseases, Bethesda, Md

$22{ }^{\mathrm{b}}$ Board of Directors, Food Allergy Research \& Education, McLean, Va, Former CEO,

23 Food Allergy \& Anaphylaxis Network

24 'Division of Allergy and Immunology, Cincinnati Children's Hospital Medical Center

25 University of Cincinnati, Cincinnati, Ohio

$26{ }^{\mathrm{d}}$ Food Allergy Research \& Education, McLean, Va, Division of Allergy and Clinical

27 Immunology, University of Michigan Health System, Ann Arbor, MI

$28{ }^{\mathrm{e}}$ Department of Dermatology, University of Rochester Medical Center, Rochester, NY

29 f National Eczema Association, San Rafael, Calif

$30{ }^{\mathrm{g}}$ Department of Nutritional Sciences, Rutgers University, New Brunswick, NJ

$31{ }^{\mathrm{h}}$ Division of Allergy and Immunology, Department of Pediatrics, BC Children's Hospital

32 University of British Columbia, Vancouver, Canada

33 i Departments of Dermatology and Pediatrics, University of California, San Diego School

34 of Medicine, Rady Children's Hospital, San Diego, Cali

35 jSection of Allergy and Immunology, Department of Pediatrics, Children's Hospital

36 Colorado, University of Colorado Denver School of Medicine, Aurora, Colo

$37{ }^{\mathrm{k}}$ Division of Gastroenterology, Hepatology, and Nutrition, Department of Pediatrics,

38 University of Kentucky College of Medicine, Kentucky Children's Hospital

39 Lexington, Ky

40 'Digestive Health Institute, Children's Hospital Colorado, Aurora, Colo

41 Section of Pediatric Gastroenterology, University of Colorado Denver School of

42 Medicine, Aurora, Colo

$43{ }^{\mathrm{m}}$ Division of Academic General Pediatrics and Primary Care, Department of Pediatrics

44 Ann and Robert H. Lurie Children's Hospital of Chicago, Northwestern University

45 Feinberg School of Medicine, Chicago, IL

$46{ }^{\mathrm{n}}$ Northwestern Medicine, Central DuPage Hospital, Winfield, IL

$47{ }^{\circ}$ Division of Allergy and Immunology, Department of Pediatrics, University of Arkansas

48 for Medical Sciences, Arkansas Children's Hospital, Little Rock, Ark

$49 \quad{ }^{\mathrm{p}}$ Metro DC Food Allergy Support Group, Rockville, Md

$50 \quad{ }^{\mathrm{q}}$ Food Allergy Referral Centre, Department of Women and Child Health, Padua

51 University Hospital, Padua, Italy

This article is protected by copyright. All rights reserved 
$52{ }^{\mathrm{r}}$ University of Missouri-Kansas City School of Medicine, Kansas City, MO

$53{ }^{\mathrm{s}}$ Division of Allergy and Immunology, Department of Pediatrics, Icahn School of

54 Medicine at Mount Sinai, New York, NY

55 'Division of Allergy and Immunology, Boston Children's Hospital, Boston, Mass

56 univision of Pediatric Allergy and Immunology, Icahn School of Medicine at Mount

57 Sinai, New York, NY

58 'Department of Pediatrics, Division of Dermatology, Seattle Children's Hospital,

59 University of Washington School of Medicine, Seattle, Wash

$60{ }^{\mathrm{w}}$ Division of Allergy and Immunology, Department of Pediatrics, The Children's Hospital

61 of Philadelphia, Perelman School of Medicine at University of Pennsylvania,

62 Philadelphia, $\mathrm{Pa}$

$63{ }^{\mathrm{x}}$ Department of Pediatrics, Section of Allergy and Immunology, Nationwide Children's

64 Hospital, Ohio State University College of Medicine, Columbus, Ohio

$65{ }^{\mathrm{y}}$ Division of Allergy and Immunology, Cincinnati Children's Hospital Medical Center

66 Cincinnati, Ohio

$67{ }^{\mathrm{z}}$ Departments of Medicine and Pediatrics, Harvard Medical School, Boston, Mass

68

69 Corresponding Author

70 Susan F. Cooper, MSc

71 Division of Allergy, Immunology, and Transplantation

72 National Institute of Allergy and Infectious Diseases

73 National Institutes of Health

745601 Fishers Lane, Room 7C28

75 Rockville, Md 20892

76

77 Telephone: 240-627-3493

78 Fax: 240-627-3113

79 E-mail: coopersu@ niaid.nih.gov

80 INTRODUCTION

81 
Food allergy is an important public health problem because it affects children and

83 adults, it may be severe and even life-threatening, and it may be increasing in prevalence.

84 Beginning in 2008, the National Institute of Allergy and Infectious Diseases (NIAID),

85 working with other organizations and advocacy groups, led the development of the first

86 clinical guidelines for the diagnosis and management of food allergy. These guidelines, ${ }^{1}$

87 which were published in 2010, did not offer strategies for the prevention of food allergy

88 due to a lack of definitive studies at the time.

In February 2015, the New England Journal of Medicine published the results of

91 the "Learning Early about Peanut Allergy" (LEAP) trial. This landmark clinical trial

92 showed that introduction of peanut products into the diets of infants at high risk of

93 developing peanut allergy was safe and led to an 81 percent relative reduction in the

94 subsequent development of peanut allergy. The LEAP trial results, combined with other

95 emerging data, strongly suggested that peanut allergy can be prevented through

96 introduction of peanut-containing foods beginning in infancy. This growing body of

97 evidence raised the need for clinical recommendations focusing on peanut allergy

98 prevention.

To achieve this goal and its wide implementation, NIAID invited the members of

101 the 2010 Guidelines Coordinating Committee and other stakeholder organizations to

102 develop this addendum on peanut allergy prevention to the 2010 Guidelines for the

103 Diagnosis and Management of Food Allergy in the United States.

DEVELOPMENT OF THE 2017 ADDENDUM TO THE 2010 GUIDELINES FOR THE DIAGNOSIS AND MANAGEMENT OF FOOD ALLERGY

111 addendum for accuracy, practicality, clarity, and broad utility of the recommendations in

112 clinical practice; review and approve the final addendum; and disseminate the addendum. 
113 The CC members represented 26 professional organizations, advocacy groups, and 114 federal agencies.

\section{Expert Panel}

116 In June 2015, the CC convened an Expert Panel (EP) that was chaired by Joshua

117 Boyce, MD. The 26 panel members, listed in Appendix B, were specialists from a variety

118 of relevant clinical, scientific, and public health areas. Panel members were nominated

119 by the CC organizations, and the composition of the panel received unanimous approval

120 by the CC member organizations.

121 The charge to the EP was to use the literature review prepared by the NIAID, in 122 conjunction with consensus expert opinion and EP-identified supplementary documents,

123 to develop evidence-based recommendations for the early introduction of dietary peanut

124 to prevent peanut allergy. The new guidelines are intended to supplement and modify

125 Guidelines 37 to 40 in Section 5.3.4 of the 2010 Guidelines: "Prevention of Food

126 Allergy."

\section{Literature review}

128 NIAID staff conducted a literature search of PubMed, limited to the years 2010

129 (January) to 2016 (June). Sixty four publications (original research articles,

130 editorials/letters, and systematic reviews) were deemed relevant and placed into 2 tiers:

131 tier 1 contained 18 items, considered highly relevant to the early introduction of peanut or

132 other allergenic foods; and tier 2 contained 46 items on related topics such as food allergy

133 or eczema prevention.

134 Assessing the quality of the body of evidence

135 For the tier 1 references, the EP assessed the quality using the Grading of

136 Recommendations Assessment, Development and Evaluation (GRADE) approach.

137 Preparation of the addendum

138 Draft versions of the addendum were reviewed by the CC members, open to

139 public comment, revised accordingly, and approved by the EP and the CC. 


\section{DEFINING THE STRENGTH OF EACH CLINICAL GUIDELINE}

142 The EP has used the verb "recommends" or "suggests" for each clinical

143 recommendation. These words convey the strength of the recommendation, defined as

144 follows:

145 - Recommend is used when the EP strongly recommended for or against a particular

146 course of action.

- Suggest is used when the EP weakly recommended for or against a particular

\section{ADDENDUM GUIDELINES}

151 The EP came to consensus on the following 3 definitions used throughout the addendum guidelines.

- Severe eczema is defined as persistent or frequently recurring eczema with typical morphology and distribution assessed as severe by a health care provider and requiring frequent need for prescription-strength topical corticosteroids, calcineurin inhibitors, or other anti-inflammatory agents despite appropriate use of emollients.

- Egg allergy is defined as a history of an allergic reaction to egg and a skin prick test (SPT) wheal diameter of $3 \mathrm{~mm}$ or greater with egg white extract, or a positive oral egg food challenge result.

- A specialist is defined as a health care provider with the training and experience to (1) perform and interpret SPTs and oral food challenges (OFC) and (2) know and manage their risks. Such persons must have appropriate medications and equipment on site.

\section{TABLE I: Summary of addendum guidelines 1, 2, and 3}




\begin{tabular}{|c|c|c|c|}
\hline $\begin{array}{l}\text { Addendum } \\
\text { guideline }\end{array}$ & Infant criteria & Recommendations & $\begin{array}{l}\text { Earliest age of } \\
\text { peanut } \\
\text { introduction }\end{array}$ \\
\hline 1 & $\begin{array}{l}\text { Severe } \\
\text { eczema, egg } \\
\text { allergy, or both }\end{array}$ & $\begin{array}{l}\text { Strongly consider evaluation by } \\
\text { sIgE and/or SPT and, if } \\
\text { necessary, an oral food } \\
\text { challenge. Based on test results, } \\
\text { introduce peanut-containing } \\
\text { foods }\end{array}$ & 4 to 6 months \\
\hline 2 & $\begin{array}{l}\text { Mild-to- } \\
\text { moderate } \\
\text { eczema }\end{array}$ & $\begin{array}{l}\text { Introduce peanut-containing } \\
\text { foods }\end{array}$ & Around 6 months \\
\hline 3 & $\begin{array}{l}\text { No eczema or } \\
\text { any food } \\
\text { allergy }\end{array}$ & $\begin{array}{l}\text { Introduce peanut-containing } \\
\text { foods }\end{array}$ & $\begin{array}{l}\text { Age appropriate } \\
\text { and in accordance } \\
\text { with family } \\
\text { preferences and } \\
\text { cultural practices }\end{array}$ \\
\hline
\end{tabular}

\section{Addendum guideline 1}

173 The EP recommends that infants with severe eczema, egg allergy, or both have

174 introduction of age-appropriate peanut-containing food as early as 4 to 6 months of age to

175 reduce the risk of peanut allergy. Other solid foods should be introduced before peanut-

176 containing foods to show that the infant is developmentally ready. The EP recommends

177 that evaluation with peanut-specific IgE (peanut sIgE) measurement, SPTs, or both be

178 strongly considered before introduction of peanut to determine if peanut should be

179 introduced and, if so, the preferred method of introduction. To minimize a delay in 180 peanut introduction for children who may test negative, testing for peanut sIgE may be

181 the preferred initial approach in certain health care settings, such as family medicine,

182 pediatrics, or dermatology practices, in which skin prick testing is not routine. 
183 Alternatively, referral for assessment by a specialist may be an option if desired by the

184 health care provider and when available in a timely manner.

185

186

187

188

189

190

191 FIG

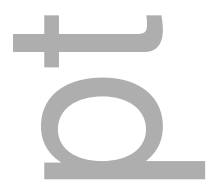

$\square$
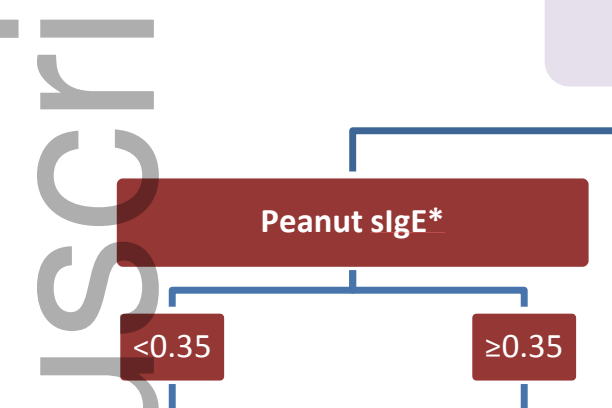

Risk of reaction low.

Over $90 \%$ will have (-) SPT to

peanut.

Options:

a) introduce peanut at home

b) Supervised feeding in the office

(based on provider/ parental preference)

\section{Severe eczema}

or

Egg allergy

or

Both

192 1:

193 Recommended approaches for evaluation of children with severe eczema and/or egg

194 allergy before peanut introduction

195

*To minimize a delay in peanut introduction for children who may test negative, testing for peanutspecific IgE may be the preferred initial approach in certain health care settings. Food allergen panel testing or the addition of SIgE testing for foods other than peanut is not recommended due to poor positive predictive value.

Refer to specialist for

consultation/SPT protocol

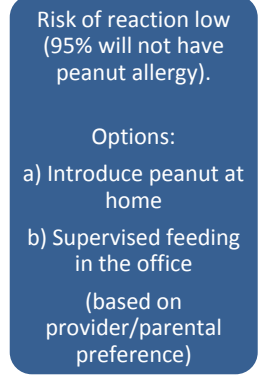

Risk of reaction varies

from moderate to

high.

Options:

a) Supervised feeding

in office

b) Graded OFC in a

specialized facility

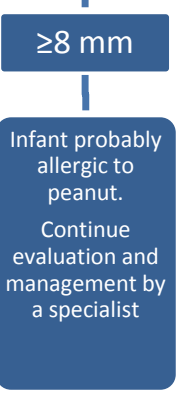

preferend 
$f$ the

\section{Important considerations for skin prick testing}

SPT reagents, testing devices, and methodology can differ significantly among health care providers in the United States or elsewhere. The EP recommends that specialists should adjust their SPT categorization criteria according to their own training and

decision is made to introduce dietary peanut based on the recommendations of addendum guideline 1, the total amount of peanut protein to be regularly consumed per week should be approximately 6 to 7 grams over 3 or more feedings.

SPT responses should be aware that the probability of a positive challenge increases

$$
\text { I }
$$

with wheal size.

218 Contribution of expert opinion. Significant.

\section{Quality of evidence. Moderate.}

The designation of the quality of evidence as "moderate" (as opposed to "high") is based on the fact that this recommendation derives primarily from a single randomized, open-label study: the LEAP trial. However, it should be noted that the assessment of the LEAP trial's primary outcome was based on a double-blind, placebo-controlled OFC. Furthermore, confidence in this recommendation is bolstered by the large effect size demonstrated in the LEAP trial and prior epidemiological data that peanut allergy is relatively infrequent in Israel, where early childhood consumption of peanut is common.

\section{Additional comments.}

1) Breast-feeding recommendations: The EP recognizes that early introduction of peanut may seem to depart from recommendations for exclusive breast-feeding through 6 months of age. However, it should be noted that data from the nutrition analysis of the LEAP cohort indicate that introduction of peanut did not affect the duration or frequency of breast-feeding, and did not influence growth or nutrition.

2) Age of peanut introduction: For children with severe eczema, egg allergy, or both, the EP recommends that introduction of solid foods begins at 4 to 6 months of age, 
starting with solid food other than peanut. However, it is important to note that the infants in the LEAP trial were enrolled between 4 and 11 months of age and benefitted from peanut consumption regardless of age at entry. Therefore, if the 4- to 6-month time window is missed for any reason, including developmental delay, infants may still benefit from early peanut introduction.

3) Considerations for family members with established peanut allergy: The EP

- recognizes that many infants eligible for early peanut introduction under this guideline will have older siblings or caregivers with established peanut allergy. The EP recommends that in this situation caregivers discuss with their health care providers the overall benefit (reduced risk of peanut allergy in the infant) versus risks (potential for further sensitization and accidental exposure of the family member to peanut) of adding peanut to the infant's diet.

4) Children identified as allergic to peanut: For children who have been identified as allergic to peanut, the EP recommends strict peanut avoidance. This may include those children who fail the supervised peanut feeding or the OFC, or those children who, upon further evaluation by a specialist, are confirmed as being allergic to peanut. These children should be under long-term management by a specialist.

of age-appropriate peanut-containing food around 6 months of age, in accordance with

249 family preferences and cultural practices, to reduce the risk of peanut allergy. Other solid 250 foods should be introduced before peanut-containing foods to show that the infant is 251 developmentally ready. The EP recommends that infants in this category may have 252 dietary peanut introduced at home without an in-office evaluation. However, the EP 253 recognizes that some caregivers and health care providers may desire an in-office

254 supervised feeding, evaluation, or both.

255 Quality of evidence. Low.

256 The quality of evidence is low because this recommendation is based on extrapolation 257 of data from a single study. 
Contribution of expert opinion. Significant.

\section{Addendum guideline 3}

261 The EP suggests that infants without eczema or any food allergy have age-appropriate peanut-containing foods freely introduced in the diet together with other solid foods and in accordance with family preferences and cultural practices.

264 Quality of evidence. Low.

265 Contribution of expert opinion. Significant.

http://www.eatright.org/

Alison Steiber PhD, RD

280 http://www.allergyasthmanetwork.org/main/

281 Tonya A. Winders, MBA

\section{American Academy of Allergy, Asthma \& Immunology (AAAAI)}

https://www.aaaai.org/home.aspx

Hugh A. Sampson, MD 
288 American Academy of Family Physicians (AAFP)

289 http://www.aafp.org/home.html

290 Jason Matuszak, MD

291

292 American Academy of Dermatology (AAD)

293 https://www.aad.org/

294 Lawrence F. Eichenfield, MD, FAAD

295 Jon Hanifin, MD

296

297 American Academy of Emergency Medicine (AAEM)

298 http://www.aaem.org/

299 Joseph P. Wood, MD, JD

300

301 American Academy of Pediatrics (AAP)

302 https://www.aap.org

303 Scott H. Sicherer, MD, FAAP

304

305 American Academy of Physician Assistants (AAPA)

306 https://www.aapa.org/

307 Gabriel Ortiz, MPAS, PA-C, DFAAPA

308

309 American College of Allergy, Asthma and Immunology (ACAAI)

310 http://acaai.org/

311 Amal Assa'ad, MD

312

313 American College of Gastroenterology (ACG)

314 http://gi.org/

315 Steven J. Czinn, MD, FACG

316

317 American Partnership for Eosinophilic Disorders (APFED)

318 http://apfed.org/

This article is protected by copyright. All rights reserved 
319 Wendy Book, MD

320

321 American Society for Nutrition (ASN)

322 http://www.nutrition.org/

323 George J. Fuchs, III, MD

324

325 Asthma and Allergy Foundation of America (AAFA)

326 http://www.aafa.org/

327 Meryl Bloomrosen, MBA, MBI

328 David R. Stukus, MD

329

330 Canadian Society of Allergy and Clinical Immunology (CSACI)

331 http://www.csaci.ca/

332 Edmond Chan, MD, FRCPC

333

334 Eunice Kennedy Shriver National Institute of Child Health \& Human Development

335 (NICHD)

336 https://www.nichd.nih.gov

337 Gilman Grave, MD

338

339 European Academy of Allergy and Clinical Immunology (EAACI)

340 http://www.eaaci.org/

341 Antonella Muraro, $\mathrm{MD}, \mathrm{PhD}$

342

343 Food Allergy Research \& Education (FARE)

344 https://www.foodallergy.org/

345 James R. Baker, MD

346 Mary Jane Marchisotto

347

348 National Eczema Association (NEA)

349 http://nationaleczema.org/

This article is protected by copyright. All rights reserved 
Julie Block

351

352 National Heart, Lung, and Blood Institute (NHLBI)

353 http://www.nhlbi.nih.gov/

354 Janet M.de Jesus, MS, RD

355

356 National Institute of Allergy and Infectious Diseases (NIAID)

357 http://www.niaid.nih.gov/

358 Daniel Rotrosen, MD

359 Alkis Togias, MD

360 Marshall Plaut, MD

361

362 National Institute of Arthritis and Musculoskeletal and Skin Diseases (NIAMS)

363 http://www.niams.nih.gov/

364 Ricardo Cibotti, $\mathrm{PhD}$

365

366 National Institute of Diabetes and Digestive and Kidney Diseases (NIDDK)

367 www.niddk.nih.gov

368 Frank Hamilton, MD, MPH

369 Margaret A. McDowell, PhD, MPH, RD (retired)

370 Rachel Fisher, MS, MPH, RD

371

372 North American Society for Pediatric Gastroenterology, Hepatology and Nutrition

373 (NASPGHAN)

374 http://www.naspghan.org/

375 Glenn Furuta, MD

376

377 Society of Pediatric Nurses (SPN)

378 http://www.pedsnurses.org/

379 Michele Habich, DNP, APN/CNS, CPN

380

This article is protected by copyright. All rights reserved 
381 United States Department of Agriculture (USDA)

382 http://www.usda.gov/

383 Soheila J. Maleki, PhD

384

385 World Allergy Organization (WAO)

386 http://www.worldallergy.org/

387 Lanny J. Rosenwasser, MD

388 APPENDIX B: EXPERT PANEL, JUNE 2015

389

390 Chair

391 Joshua A. Boyce, MD

392 Professor of Medicine and Pediatrics

393 Harvard Medical School

394 Director, Inflammation and Allergic Disease Research Section

395 Director, Jeff and Penny Vinik Center for Allergic Disease Research

396 Specialty: Allergy/pediatric pulmonology

398 Panelists

399 Maria Acebal, JD

400 Board of Directors, Food Allergy Research \& Education

401 Member of NIAID Advisory Council

402 Former CEO of Food Allergy and Anaphylaxis Network

403 Specialty: Advocacy

404

405 Amal Assa'ad, MD

406 Professor, University of Cincinnati Department of Pediatrics

407 Director, FARE Center of Excellence in Food Allergy

408 Director of Clinical Services, Division of Allergy and Immunology

409 Associate Director, Division of Allergy and Immunology

410 Cincinnati Children's Hospital Medical Center

411 Specialty: Allergy/pediatrics

This article is protected by copyright. All rights reserved 


\section{James R. Baker Jr, MD}

414 CEO and Chief Medical Officer

415 Food Allergy Research \& Education, McLean VA

416 Founding Director, Mary H. Weiser Food Allergy Center, University of Michigan

417 Professor of Internal Medicine, Division of Allergy and Clinical Immunology

418 University of Michigan Health System

419 Specialty: Allergy/advocacy/education

420

421 Lisa A. Beck, MD

422 Professor, Department of Dermatology

423 University of Rochester Medical Center

424 School of Medicine and Dentistry

425 Specialty: Dermatology

426

427 Julie Block

428 President and CEO

429 National Eczema Association

430 Specialty: Advocacy/education

432 Carol Byrd-Bredbenner, PhD, RD, FAND

433 Professor of Nutrition/Extension Specialist

434 Rutgers University, School of Environmental and Biological Sciences

435 Specialty: Nutrition/health communication/behavioral science

437 Edmond S. Chan, MD, FRCPC

438 Clinical Associate Professor

439 Head, Division of Allergy and Immunology

440 Department of Pediatrics

441 BC Children's Hospital

442 University of British Columbia 
443 Specialty: Allergy/pediatrics

444

445 Lawrence F. Eichenfield, MD

446 Professor of Pediatrics and Dermatology

447 Chief, Pediatric and Adolescent Dermatology

448 Rady Children's Hospital, San Diego

449 University of California, San Diego School of Medicine

450 Specialty: Dermatology/pediatrics

452 David M. Fleischer, MD

453 Associate Professor of Pediatrics

454 University of Colorado School of Medicine

455 Children's Hospital Colorado, Aurora, CO

456 Specialty: Allergy/pediatrics

457

458 George J. Fuchs III, MD

459 Professor of Pediatrics

460 University of Kentucky College of Medicine

461 Chief, Gastroenterology, Nutrition \& Hepatology

462 Kentucky Children's Hospital

463 Specialty: Gastroenterology/pediatrics

465 Glenn T. Furuta, MD

466 Professor of Pediatrics

467 Director, Gastrointestinal Eosinophilic Diseases Program

468 University of Colorado School of Medicine

469 Children's Hospital Colorado, Aurora, CO

470 Specialty: Gastroenterology/pediatrics

471

472 Matthew J. Greenhawt, MD MBA, MSc

473 Assistant Professor of Pediatrics 
474 Allergy Section

475 University of Colorado School of Medicine

476 Children's Hospital Colorado, Aurora, CO

477 Specialty: Allergy/pediatrics

478

479 Ruchi Gupta, MD, MPH

480 Associate Professor of Pediatrics and Medicine

481 Director, Food Allergy Outcomes Research Program

482 Ann and Robert H. Lurie Children's Hospital of Chicago

483 Northwestern Medicine, Northwestern University

484 Specialty: Pediatrics

485

486 Michele Habich, DNP, APN/CNS, CPN

487 Advanced Practice Nurse

488 Northwestern Medicine, Central DuPage Hospital

489 Specialty: Nursing/pediatrics/education

490

491 Stacie M. Jones, MD

492 Professor of Pediatrics

493 University of Arkansas for Medical Sciences

494 Chief, Allergy and Immunology

495 Arkansas Children's Hospital

496 Specialty: Allergy/pediatrics

497

498 Kari Keaton

499 Facilitator, Metro DC Food Allergy Support Group

500 Specialty: Advocacy/education

501

502 Antonella Muraro, MD, PhD

503 President of European Academy of Allergy and Clinical Immunology (EAACI)

504 Professor of Allergy and Pediatric Allergy 
505 Head of the Veneto Region Food Allergy Centre of Excellence for Research and

506 Treatment

507 University Hospital of Padua, Italy

508 Specialty: Allergy/pediatrics

509

510 Lanny J. Rosenwasser, MD

511 Immediate Past President, World Allergy Organization

512 Professor of Medicine

513 University of Missouri-Kansas City-School of Medicine

514 Specialty: Allergy/pediatrics

515

516 Hugh A. Sampson, MD

517 Professor of Pediatrics, Allergy and Immunology

518 Icahn School of Medicine at Mount Sinai

519 Director, Jaffe Food Allergy Institute

520 Specialty: Allergy/pediatrics

521

522 Lynda C. Schneider, MD

523 Professor of Pediatrics

524 Harvard Medical School

525 Director, Allergy Program

526 Boston Children's Hospital

527 Specialty: Allergy/pediatrics

528

529 Scott H. Sicherer, MD

530 Professor Pediatrics, Allergy and Immunology

531 Icahn School of Medicine at Mount Sinai

532 Division Chief, Pediatric Allergy and Immunology

533 Specialty: Allergy/pediatrics

534

535 Robert Sidbury, MD, MPH

This article is protected by copyright. All rights reserved 
536 Professor

537 Department of Pediatrics

538 Chief, Division of Dermatology

539 Seattle Children's Hospital

540 University of Washington School of Medicine

541 Specialty: Dermatology/pediatrics

542

543 Jonathan Spergel, MD, PhD

544 Stuart Starr Professor of Pediatrics

545 Chief, Allergy Section

546 Director, Center for Pediatric Eosinophilic Disorders

547 The Children's Hospital of Philadelphia

548 Perelman School of Medicine, University of Pennsylvania

549 Specialty: Allergy/pediatrics

550

551 David R. Stukus, MD

552 Assistant Professor of Pediatrics

553 Section of Allergy/Immunology

554 Nationwide Children's Hospital

555 Columbus, $\mathrm{OH}$

556 Specialty: Allergy/pediatrics

557

558 Carina Venter, PhD, RD

559 Allergy Specialist, Dietitian

560 Cincinnati Children's Hospital Medical Center

561 University of Cincinnati College of Medicine

562 Specialty: Allergy/dietitian/pediatrics

563 Abbreviations used

564 CC: Coordinating Committee

565 EP: Expert Panel

566 GRADE: Grading of Recommendations Assessment, Development and Evaluation 
567 LEAP: Learning Early about Peanut Allergy

568 NIAID: National Institute of Allergy and Infectious Diseases

569 OFC: Oral food challenge

570 sIgE: Specific Immunoglobulin E

571 SPT: Skin prick test

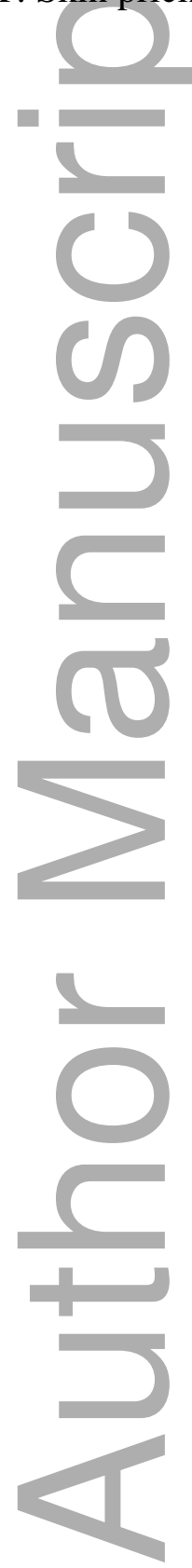

This article is protected by copyright. All rights reserved 


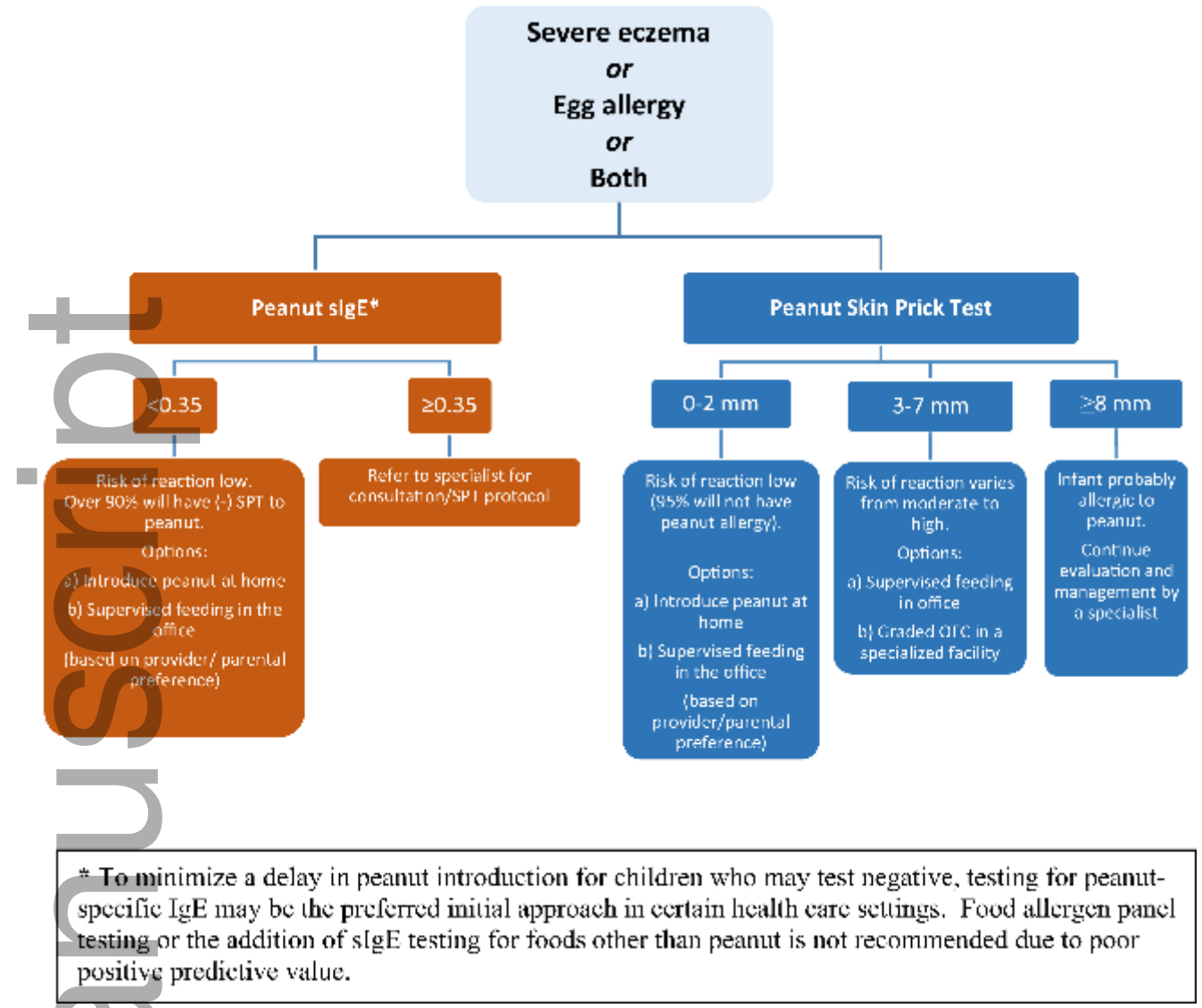

pde_13092_f1.jpg 